\title{
Visual Search for Size Is Influenced by a Background Texture Gradient
}

\author{
Deborah J. Aks \\ University of Wisconsin at Whitewater
}

\author{
James T. Enns \\ University of British Columbia
}

\begin{abstract}
Research on the perception of texture gradients has relied heavily on the subjective reports of observers engaged in free-viewing. We asked whether these findings generalized to speeded performance. Experiment 1 showed that an important aspect of subjective perception-sizeconstancy scaling with perceived distance--also predicted the speed of pop-out visual search for cylinders viewed against a texture gradient. Experiment 2 showed that this finding could not be attributed to the local contrast between search items and the background texture. Experiment 3 assessed the relative contributions of 2 separable dimensions of texture gradients-perspective (radial spreading) and compression (foreshortening)-finding them to be independent in the more rapid search conditions (long target among shorter distractors) but combined in their influence in the slower conditions (short target among longer distractors).
\end{abstract}

When observers view the texture gradient shown in Figure $1 \mathrm{~A}$ they usually report seeing a flat surface recede into the distance, despite the fact that a two-dimensional (2-D) image alone cannot specify the three-dimensional (3-D) surface that gave rise to the projection. This study asked whether the factors influencing the perceived slant of such texture gradients also influences rapid visual search for objects placed on their surface.

Although a large number of previous studies have examined the perception of slant in texture gradients (e.g., Flock, 1965; Gibson, 1950a, 1950b, 1979; Pizlo \& Rosenfeld, 1992; Stevens, 1981, 1983a, 1983b; Todd \& Akerstrom, 1987; Witkin, 1981), most have relied on the subjective reports of observers. For example, observers in Gibson's (1950b) pioneering work matched the slant of textured surfaces in photographs by using their palms to show a corresponding inclination. The more recent studies have used variations on this method. We wondered whether the findings obtained with these measures would generalize to a performance-based measure.

This question arose quite naturally from our concern for the larger issue of ecological validity. We noted that researchers who use naturalistic stimuli to study perception under ecologically valid conditions do not necessarily show the same consideration for the observer's task. Observers are typically given unlimited time to view the stimulus and to produce a slant estimate. This task is not related in any direct way to the everyday actions for which the visual system is used, ranging from those that are essential for the survival of an individual or the species (e.g., feeding, fight-

Deborah J. Aks, Department of Psychology, University of Wisconsin at Whitewater; James T. Enns, Department of Psychology, University of British Columbia, Vancouver, British Columbia, Canada.

Correspondence concerning this article should be addressed to Deborah J. Aks, Department of Psychology, University of Wisconsin, Whitewater, Wisconsin 53190 . Electronic mail may be sent via the Internet to aksd@uwwvax.uww.edu. ing, fleeing, and mating) to those that are engaged in largely for pleasure (e.g., playing sports or video games). What these tasks all have in common is that there is an advantage to be gained by using vision rapidly to control actions (e.g. eye and head movements in visual exploration, hand movements in grasping, and foot movements in locomotion). From this perspective, studies based on observer reports tell us only that the depicted distance in a texture gradient can form the basis of a conscious percept under conditions of focused attention.

There are now a handful of studies in which the perception of texture gradients has been assessed under stress of time (Bennett \& Warren, 1993; Leibowitz \& Bourne, 1956; Pringle \& Uhlarik, 1982; Smets \& Stappers, 1990; Uhlarik, Pringle, Jordan, \& Misceo, 1980). Of these, Bennett and Warren (1993) came closest to the present goal. Observers were shown displays of a textured hallway against which shapes were presented in a same-different shape matching task. For this task, differences in shape and size were irrelevant, and it was in the observer's interest to ignore them. Nonetheless, reliable influences on response time (RT) were found for both environmental size (depth scaled) and retinal size (visual angle) differences. However, the challenging nature of the task (i.e., RTs in the shapematching task averaged 1-2 s) suggested that observers scrutinized the shapes with focused attention.

Smets and Stappers (1990) presented observers with brief exposures of a texture gradient-the task was to detect a texture element oriented inappropriately in its immediate context. Detection accuracy was clearly dependent on the extent to which the gradient was disrupted, with the authors interpreting this as evidence for very rapid processing of slant from texture gradients. However, the possibility that the task was accomplished using local 2-D cues could not be ruled out. Furthermore, the task again forced observers to attend to the texture elements in making their report, leaving open the possibility that focused attention was involved in the effects.

The task we used involved searching for a target cylinder 
A

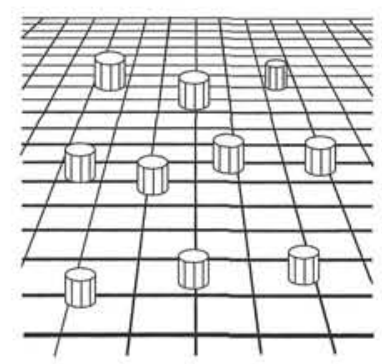

B

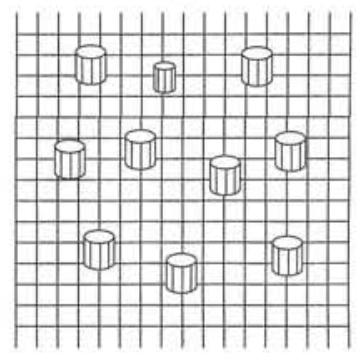

Figure 1. Texture gradients consisting of a grid of lines. Superimposed on each gradient are 10 outline drawings of cylinders, one of which (the target) is smaller than the others. (A) The gradient is consistent with a surface slanted at $77^{\circ}$ away from the frontoparallel plane of the viewer. (B) The texture is uniform, or slanted $0^{\circ}$ from the frontoparallel plane.

that was either larger or smaller than nontarget (distractor) cylinders, as shown in Figure 1A. If the apparent size of the search items is influenced by the background texture gradient, it should be easiest when retinal target size is inconsistent with its location in the image (e.g., a long target shown in a "far" location or a short target shown in a "near" location) and most difficult when retinal target size is consistent with location (e.g., a long target shown in a "near" location or a short target shown in a "far" location).

\section{Experiment 1: Visual Search Is Influenced by a Background Texture Gradient}

The first experiment we report in detail benefited from several preliminary tests (Aks, 1993). In one, the search items were black bars of various lengths, designed to be comparable to those used in other studies (e.g., Treisman \& Gormican, 1988). However, they yielded unreliable effects across background location. The items seemed to be easily segregated from the background texture, either because of their 2-D appearance, or their lack of apparent contact with the depicted surface, or both. We therefore tested items that had both apparent volume and appeared to contact the slanted surface.

In a second test, line-drawn cylinders were presented against a textured surface that receded toward the top of the display, as shown in Figure 1A. Search was indeed more difficult when a shorter target cylinder was "far" (i.e., top of the display) and a longer target cylinder was "near" (i.e., bottom of the display), but the same location effects were observed, albeit reduced in magnitude, in the control background (see Figure 1B). A possible reason is that observers may have been influenced by the height of the target in the picture plane, with height alone being interpreted as a depth cue (Bennett \& Warren, 1993, describe a similar effect).

A third test used the same stimuli shown in Figure 1, except that the displays were rotated by $90^{\circ}$ to control for any possible contribution from the depth cue of height in the plane. The slanted surface therefore appeared to be a wall rather than a floor, which could slant either to the left or to

the right. This time, the control backgrounds revealed no systematic bias for targets located on the right or the left. However, the same targets viewed against the slanted background showed strong location dependency, with the mean RT for the short target over $250 \mathrm{~ms}$ slower (and 21\% less accurate) in the far locations than in the near locations. Conversely, mean RTs for the long targets were $378 \mathrm{~ms}$ slower (and 29\% less accurate) in the near versus far locations. RT slopes (mean RT as a linear function of display size) averaged over $30 \mathrm{~ms}$ per item in each condition.

The present experiment began with the question of whether these effects would also be observed when the baseline search task was one of "pop-out," that is, when focused attention is not required for target detection. This is of interest because many theories of vision are premised on a distinction between two subsystems: a rapid preattentive system, which uses spatially parallel mechanisms, working in a bottom-up fashion, to register image features in independent topographic maps; and a later attentive system, which takes advantage of flexible, but spatially serial, topdown processes to conjoin features from shared spatialtemporal locations (Beck, 1982; Julesz, 1984; Treisman, 1986; Treisman, Cavanagh, Fischer, Ramachandran, and von der Heydt, 1990; Wolfe, 1994). These two subsystems have often been distinguished operationally on the basis of visual search RT slopes. Slopes that are less than $10 \mathrm{~ms}$ per item define pop-out or parallel search, because it is believed that the serial mechanisms of attention require more time to be able to move from item to item (or alternatively, because there is little decrease in the efficiency of spatially parallel processes with increasing display size, see Ashby \& Townsend, 1986).

More recently, the consensus has moved to the position that there is really a continuum of search slopes underlying performance. This alone, however, has not been too unsettling to the theories, because most are able to accommodate this range of performance while retaining the theoretical distinction (cf. Ashby \& Townsend, 1986; Duncan \& Humphreys, 1989; Treisman \& Gormican, 1988; Treisman \& Sato, 1990; Wolfe, 1994; Wolfe, Cave, \& Franzel, 1989). Therefore, when we refer to two systems in this article, we do so with the understanding that visual processes may really be graded.

The more troubling data for conventional theories come from reports showing that pop-out is sometimes possible for complex spatial relations among simple features-especially when those relations signal important features in the 3-D domain, such as surface orientation, convexity, stereodepth, and direction of lighting (Aks \& Enns, 1992; Enns \& Rensink, 1990a, 1990b, 1991; Kleffner \& Ramachandran, 1992; Nakayama \& Silverman, 1986; Ramachandran, 1988). These findings strongly suggest that the mechanisms of visual search have access to a level of representation that has some information about 3-D object shape and surface layout. In the present experiment we asked whether pop-out search for items differing in a simple feature (i.e., size) might also be sensitive to the depicted slant in a background texture. 


\section{Method}

Stimuli and apparatus. Display presentation and data collection were controlled by a Macintosh computer running VScope software (Enns \& Rensink, 1992). The drawings of cylinders and textured surfaces were generated by the DynaPerspective Design and Modeling Program (Tatsumi \& Okamura, 1988). Two examples of the displays are shown in Figure 1. The lines used to draw the search items and the background grid were black $\left(12.2 \mathrm{~cd} / \mathrm{m}^{2}\right)$ against a white screen $\left(158.9 \mathrm{~cd} / \mathrm{m}^{2}\right)$. The slanted background was generated by taking the control background, which consisted of a uniform square grid of lines $\left(14^{\circ} \times 14^{\circ}\right)$, and redrawing it at a $77^{\circ}$ slant relative to the normal of the line of sight. To control for location-based differences in luminance contrast in the slant background, pixel density was controlled (i.e., every $2.25^{\circ} \times 2.25^{\circ}$ region of the display contained $20 \%$ black pixels).

Search items were randomly distributed over a $6 \times 6$ grid of notional cells, with the constraint that the target item appeared equally often in each of three equal-size vertical regions. For the control background, these were simply the left-, middle-, and right-thirds of the display. For the slant backgrounds, the same regions corresponded to the relative distances of far, midrange, and near. Observers were seated, with their eyes approximately $50 \mathrm{~cm}$ from the screen.

Search items were also presented in one of two orientations: horizontally oriented cylinders were drawn so that they appeared to contact the surface of the gradient (i.e., the visible side of the cylinder was oriented to recede along with the textured surface), and vertically oriented cylinders were drawn so as to be viewed from above and thus suspended free of the textured surface.

Design and procedure. In a preliminary phase of the experiment, the size difference between target and distractor items was determined separately for each observer. We used a staircase procedure (Cornsweet, 1962) to ensure that each observer performed pop-out search (mean slope of $10 \mathrm{~ms}$ per item or less on target-present trials) for the long target in the baseline measure.

The possible targets in the staircase procedure ranged in size from $1.40^{\circ} \times 1.10^{\circ}$ to $1.72^{\circ} \times 1.42^{\circ}$ in $.04^{\circ}$ increments; distractors were held constant at $1.29^{\circ} \times .92^{\circ}$. Testing began with the largest (or smallest) target and was systematically decreased (or increased) until the target-present search slope was inside (or outside) the preattentive range $(0-10 \mathrm{~ms} / \mathrm{item})$. The direction of the steps was then reversed, and testing continued until the search rate had crossed the boundary. The average target size required to achieve this pop-out criterion after 4 to 6 sets of 60 trials was taken as the threshold for each observer. Differences in threshold size ranged from $0.25^{\circ}$ to $0.40^{\circ}$ between observers. The item size determined by this procedure was then used as the target in the long target condition and as the distractor in the short target condition of the texture-gradient experiment.

Observers made speeded bimanual responses to indicate whether a target cylinder was present in the display. On a random half of the displays, the target was present, with the total number of cylinders also varying randomly between 2,6 , and 10 .

Each trial began with a central fixation symbol (black dot) lit for $500 \mathrm{~ms}$, followed by the display, which remained visible until the observer responded. Following the response, visual feedback was presented at the center of the screen ("+" for correct, "- "for incorrect). Observers were instructed to maintain fixation throughout the trial sequence, to respond as rapidly as possible, and to keep errors below $10 \%$.

Observers were tested in two 1-hr sessions, one for the long target and one for the short target (target and distractor sizes were reversed). Each session consisted of three sets of 54 trials in the control condition and the same number of trials in the slant condition, in a counterbalanced order. Because of the large number of conditions, observers were further divided into four groups: item orientation (horizontal, vertical) and direction of slant ("near" on the right, "near" on the left).

Participants. Forty undergraduate students (24 female, age range $=17-27$ years) participated in two $1-\mathrm{hr}$ sessions. None had previous experience with visual search tasks, and all reported normal or corrected-to-normal vision.

\section{Results}

Mean correct RT and percentage errors for target present trials are presented in Table $1 .^{1}$ Preliminary analyses showed that search was easiest when the target was located in the middle region of both backgrounds. This was supported by a significant main effect of location-RT: $\mathrm{F}(2$, $76)=126.17, p<.001$; errors: $F(2,78)=28.37, p<$ .001 -and significant comparisons between middle and extreme locations for both RT and errors on each background (all $p$ s $<.05$ ).

As shown in Figure 2, visual search for short targets in the slant condition was $66 \mathrm{~ms}$ slower on average, $t(78)=8.60$, $p<.001$, and $4.4 \%$ less accurate, $t(78)=4.04, p<.001$, in the far than in the near location. Conversely, search for long targets was $27 \mathrm{~ms}$ slower, $t(78)=3.63, p<.001$, and $0.1 \%$ less accurate, $t(78)=0.01$, in the near than in the far locations. In the control condition, performance did not vary significantly for left and right locations (all $p s>.05$ ). These comparisons were supported in the overall analysis of variance (ANOVA) by the following significant interactions: Background $\times$ Target Size $\times$ Location (RT: $F[2,78]=$ $34.67, p<.001$; errors: $F[2,78]=7.58, p<.01]$; Target Size $\times$ Location $(\mathrm{RT}[F(2,78)]=15.40, p<.001)$; and Background $\times$ Location (RT: $F[2,78]=8.37, p<.001$; errors: $F[2,78]=4.20, p<.02$ ).

RT slopes (linear regression lines fit to the mean RT over display size) were not as sensitive to the texture gradients as the mean RT averaged over differences in display size. As expected, slopes showed no regional bias in the control conditions $(M=5.3 \mathrm{~ms}$ per item for long, $M=10.2 \mathrm{~ms}$ per item for short, all $p s>.20$ ). In the slant condition, there were marginal differences in slope for short targets, but these were opposite to the size-scaling prediction: near = 17.1 vs. far $=10.0 \mathrm{~ms}$ per item, $t(38)=1.86, p=.06$. Slopes were approximately the same for long targets across near and far regions: 6.8 vs. $8.7 \mathrm{~ms}$ per item, $t(38)=0.50$.

The most direct measure of the influence of size-scaling on visual search was given by a combined size-consistency score. This was obtained by first subtracting from each of the two extreme locations in the slant background (i.e., near and far locations) the corresponding data points in the

\footnotetext{
${ }^{1}$ Statistical analyses were based only on target present trials because absent trials are not differentiated by target location. Missing data were observed in $0.69 \%$ of the cells in this design, either because of a computer program failure or because there were no correct RTs observed for a given observer. These cells were filled by the group mean for statistical analyses, but in no case were the reported significance levels affected by this procedure.
} 
Table 1

Mean Correct Response Time and Mean Errors in Experiment 1

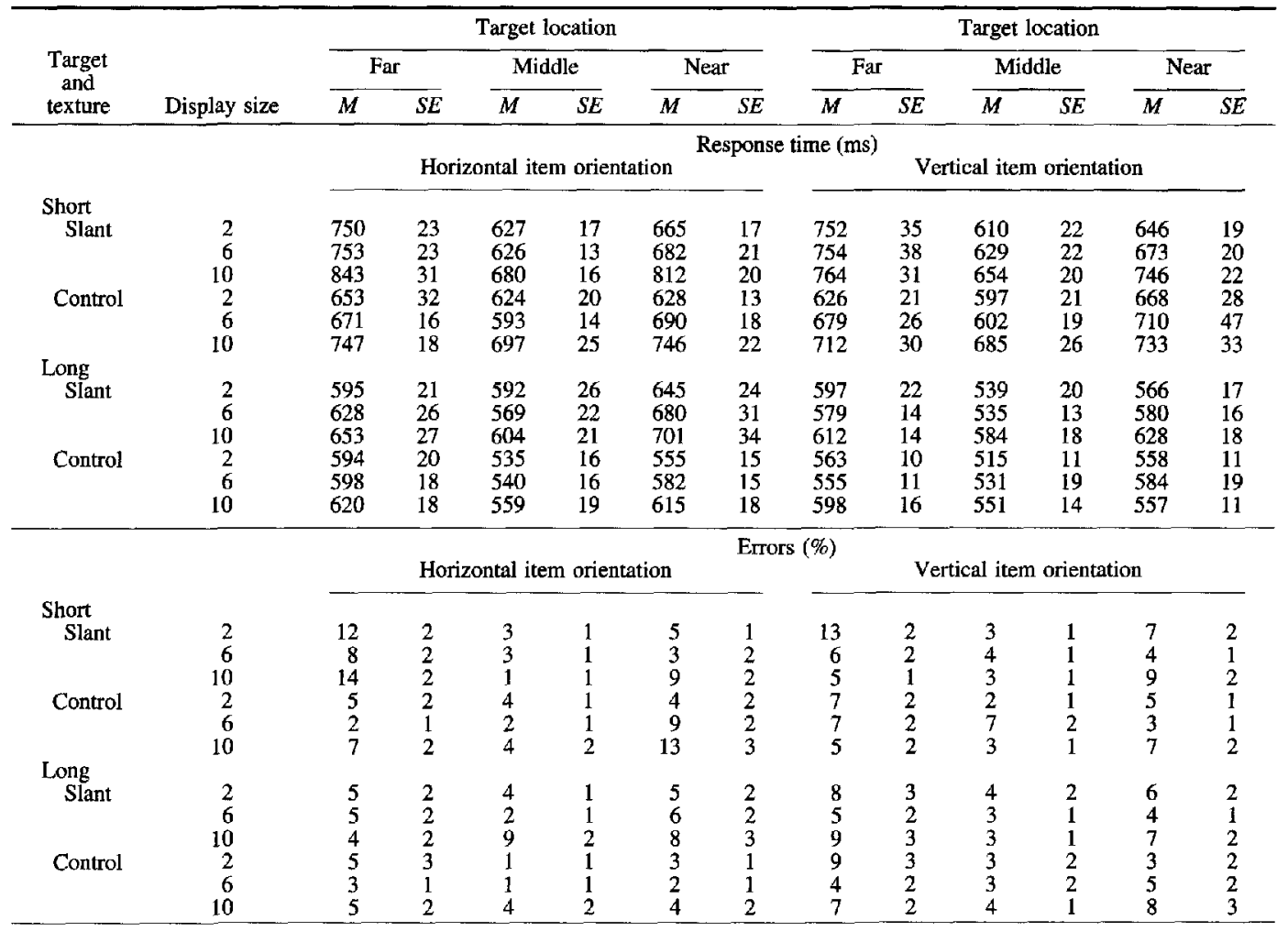

control background (i.e., left and right locations). The scores in the size-inconsistent conditions (i.e., short targets in the near location, long targets in the far location) were then subtracted from those in the consistent conditions (i.e., short targets in the far location, long targets in the near location). The difference scores in Figure 3 thus reflect the effect of apparent slant after all control factors have been taken into account.

Note that almost all conditions yielded a significant size consistency effect in RT. The two exceptions involved the vertically oriented, long target items (2- and 6-item displays). An ANOVA revealed a marginally significant effect of target size, $F(1,38)=3.91, p<.06$, reflecting the generally stronger effects for short targets. Three interactions were also significant: Target Size $\times$ Item Orientation, $F(1,38)=7.54, p<.01$, reflected smaller consistency scores for the vertical long targets $(M=8 \mathrm{~ms})$ than for the others ( $M=73 \mathrm{~ms}$ for horizontal long, $99 \mathrm{~ms}$ for vertical short, and $58 \mathrm{~ms}$ for horizontal short); whereas Target Size $\times$ Display Size, $F(2,76)=3.31, p<.05$, reflected a decline in consistency scores, with increasing display size for short targets ( $M \mathrm{~s}=102,96$, and $38 \mathrm{~ms}$, respectively) but not for long targets ( $M \mathrm{~s}=46,20$, and $55 \mathrm{~ms}$, respectively), a trend that was most pronounced when items were oriented vertically, Target Size $\times$ Display Size $\times$ Item Orientation, $F(2,76)=3.33, p<.05$.

A size-consistency analysis of the error data was generally in agreement with the RT data, although only two main effects reached significance: short targets resulted in stronger effects than long targets, $F(1,38)=7.03, p<.02$, and effects tended to diminish with increasing display size; mean errors $=8.0 \%, 2.1 \%$, and $1.9 \%$, respectively; $F(2,78)=3.54, p<.05$.

\section{Discussion}

These data show that pop-out visual search, based on a simple feature such as size, can be influenced by the slant that is depicted in a background texture gradient. Both search speed and accuracy varied with the location of the target on the texture surface-- being best when the projected size of the target was inconsistent with the depicted slant (i.e., when the short target was near or the long target was far) and worst when shown with consistent size-scaling (i.e., 


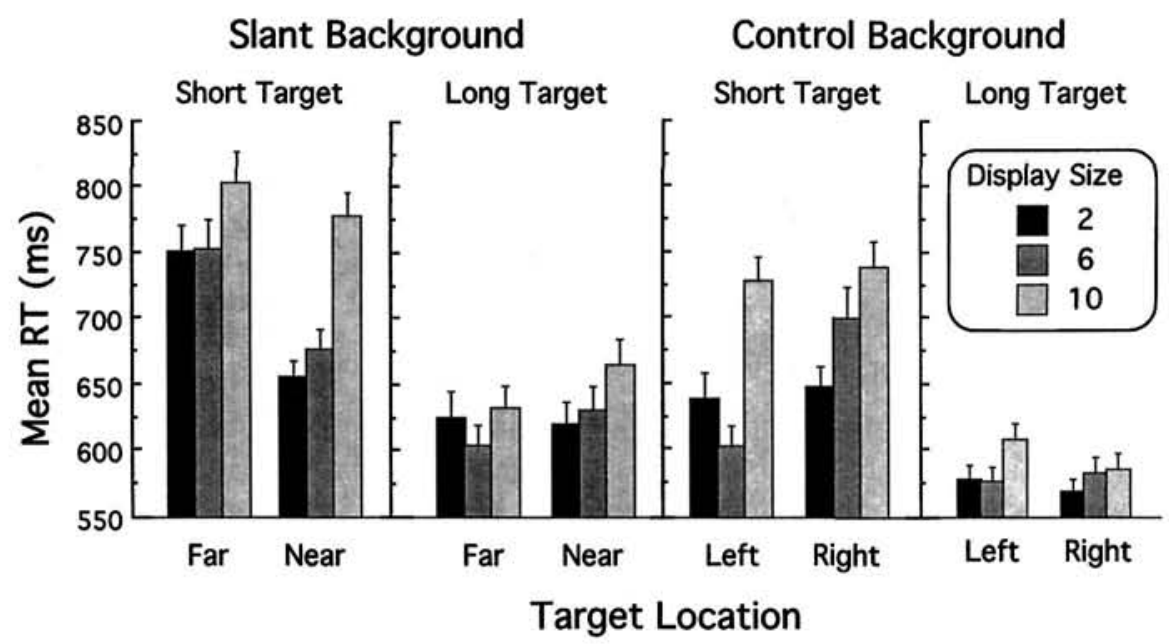

Figure 2. Mean correct response time (RT) for selected target present trials in Experiment 1. Bars in each group of three show display sizes of 2 (left bar), 6 (middle bar), and 10 (right bar).

the long target was near or the short target was far). A control condition involving a background of uniform texture also revealed a location effect (i.e., an advantage for targets in the middle region), but this could not be attributed to depicted depth. The clear implication is that the background texture gradient affects the processes underlying visual

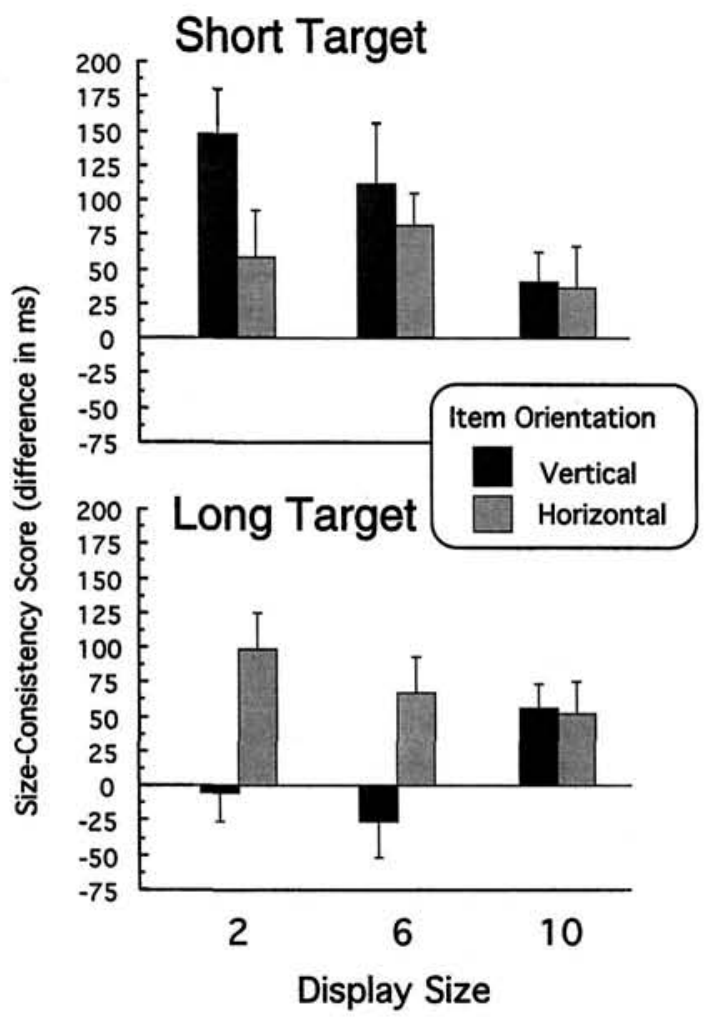

Figure 3. Size-consistency scores in Experiment 1. Bars in each group of two show vertical (left bar) and horizontal (right bar) item orientations. search and that focused attention is not necessary for the depicted slant to be processed.

The finding that the influence of the texture gradient was more reliable for the horizontally oriented than for vertically oriented cylinders further supports the hypothesis that popout search is sensitive to depicted surface slant. Recall that search items in this condition appeared to be attached to the receding background surface, whereas those in the vertical condition appeared to be suspended in front of the textured plane. This suggests that the processes underlying visual search were also sensitive to depicted "surface attachment" (Butler \& Kring, 1987).

Why was search easiest for targets in the middle location, regardless of whether the background depicted a slanted or a flat surface? There are several ready explanations, including that the efficiency of search has often been noted to increase with proximity of the target to the fovea (e.g., Carrasco, Evert, Chang, \& Katz, 1995; Wolfe, 1994) and that search is made more efficient by increased proximity between the target and distractor items (Green, 1992; Northdurft, 1992; Poisson \& Wilkinson, 1992; Sagi, 1990; Sagi \& Julesz, 1987). Both of these effects would be strongest in the middle location in the present experiment.

The one unexpected finding was that texture gradients did not influence search rates (i.e., RT slopes) as consistently as they influenced overall search speed (i.e., mean RT). One possible reason may have been the presence of a floor effect. That is, the search task may have simply been too easy in large display size conditions for the influence of the texture to be observed in the slopes.

But there are also less trivial explanations. One is premised on the idea that it is easier to compare stimuli at the same apparent depth than to compare across different depth planes. In the present displays, the probability of such comparisons increased directly with display size. ${ }^{2}$ Another account appeals to the influence of item grouping. There are several reports demonstrating the effects of item grouping at 
the earliest stages of vision (Callaghan, 1989; Callaghan, Lasaga, \& Garner, 1986; Duncan \& Humphreys, 1989; Humphreys, Quinlan, \& Riddoch, 1989; Rensink \& Enns, 1995; Treisman, 1982). Item grouping can be used both to increase the speed of search, as occurs when all nontarget items are homogeneous, or to decrease its speed, as occurs when the target is embedded in a larger gestalt-like configuration. Here, two such operations may have been at work. The first, a grouping of homogeneous distractors, should have worked to speed up search disproportionately in large display sizes, because under these conditions the items could be segmented, as a group, more easily from the background texture. The second operation, a grouping of the search items with the background surface through apparent attachment, should have worked to make size-consistent search more difficult in the horizontally oriented item conditions. Both of these effects were evident in the data.

\section{Experiment 2: Controlling for Local Texture Contrast Effects}

The second experiment was designed to control for local 2-D contrast effects. This was motivated by the observation that in our size-consistent conditions (i.e., short target in far location, long target in near) the target item was presented against a background that may have contributed locally to a more difficult search (i.e., short target presented against a fine texture, long target presented against a coarse texture). Conversely, in our size-inconsistent conditions (i.e., short target in near location, long target in far), the target item may have been more conspicuous simply because of its relation to the local background scale of texture (i.e., short target presented against a coarse texture, long target presented against a fine texture).

To examine the possible contributions of such effects, we replicated a substantial portion of Experiment 1 using a larger set of control backgrounds, as shown in Figure 4. Observers searched for a target among horizontally oriented items in both the slant condition and three control conditions that differed in background texture scale.

\section{Method}

Stimuli and apparatus. Visual search displays and items were similar to those in Experiment 1, with the following exceptions. First, the lines making up the search items and the textures (12.2 $\left.\mathrm{cd} / \mathrm{m}^{2}\right)$ were placed on a square gray background $\left(60 \mathrm{~cd} / \mathrm{m}^{2}\right)$ to delineate a $14^{\circ} \times 14^{\circ}$ texture viewing region. Second, to increase the discriminability of the search items even further, all items were filled with a slightly darker gray $\left(50 \mathrm{~cd} / \mathrm{m}^{2}\right)$. Third, control background displays consisted of three uniform-grid textures at different scales, with examples of the fine and coarse scales shown in Figure 4. These square grids correspond in shape to nonslanted surfaces used in the control condition of Experiment 1. The square grid elements matched the mean horizontal dimension of the far, middle, and near texture elements on the slanted surface. Thus, fine-control consisted of a $40 \times 40$ grid of lines each $0.05^{\circ}$ wide, medium-control consisted of a $20 \times 20$ grid in which lines were $0.10^{\circ}$ wide, and coarse-control consisted of an $11 \times 11$ grid in which lines were $0.10^{\circ}$ wide. Pixel density of the lines was again controlled (i.e., every $2.25^{\circ} \times 2.25^{\circ}$ region of the display con-
Coarse

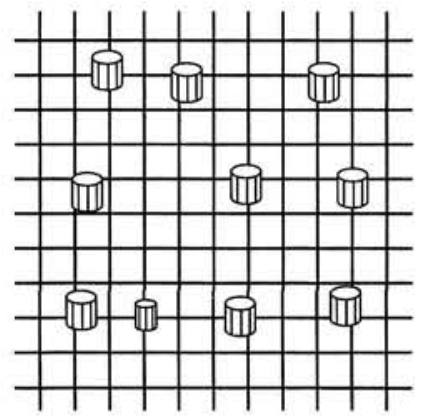

Fine

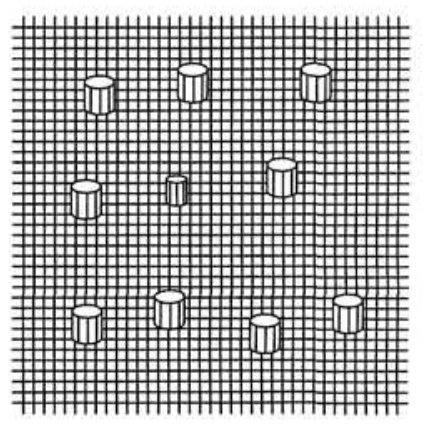

Figure 4. Two of the three control textures tested in Experiment 2 , along with 10 search items ( 1 short target and 9 distractors).

tained $20 \%$ black pixels). Fourth, target and distractor items sizes were fixed for all observers at $1.67^{\circ} \times 1.24^{\circ}$ for long items and $1.29^{\circ} \times .92^{\circ}$ for short items. Finally, all search items were horizontally oriented, because it was these items that yielded the most consistent effects.

Design and procedure. Observers performed the same visual search task as in Experiment 1, against a texture gradient (slant) and the three uniform grids (fine, medium, coarse) in a random order. Each observer was thus tested for three sets of 60 trials in each condition. All other procedural details were identical to those in Experiment 1.

Participants. Thirty undergraduate students from the University of Wisconsin (17 female; age range $=17-26$ ) participated in a $1 \mathrm{hr}$ or two $1 / 2 \mathrm{hr}$ sessions. Observers received course credit for participating, and all reported normal or corrected-to-normal vision.

\section{Results}

Mean correct RT and percentage errors are presented in Table $2,{ }^{3}$ with the specific conditions relevant to our hypotheses graphed in Figure 5. Preliminary analyses again showed that search was easiest when targets were located in the middle regions of all backgrounds-RT: $F(2,58)=$ $10.62, p<.001$; errors: $F(2,58)=7.37, p<.01$. However, they also showed that target location (left, middle, right) interacted with the scale of the texture (fine, medium, coarse) in the control backgrounds- RT: $F(4,116)=3.07$, $p<.02$; errors: $F(4,116)<1$. Specifically, there was a smaller advantage for the middle location in the mediumscale texture [ $16 \mathrm{~ms}, 1.6 \%$ ] than in the fine [ $38 \mathrm{~ms}, 1.5 \%$ ] or coarse-scale textures [ $31 \mathrm{~ms}, 2.5 \%]$. To control for location and texture scale effects as much as possible, all subsequent comparisons between slant and control conditions were made with these variables held constant (e.g., near left-side locations in the slant background were compared with left-side locations in the coarse control background).

\footnotetext{
${ }^{2}$ We thank Jeremy Wolfe for this idea.

${ }^{3}$ Missing data were observed in $0.0025 \%$ of the cells in this design, either because an original data file was lost or because there were no correct RTs observed for a given observer. As in Experiment 1, these cells were filled by the group mean for statistical analyses, but in no case were the reported significance levels affected by this procedure.
} 
Table 2

Mean Correct Response Time and Mean Errors in Experiment 2

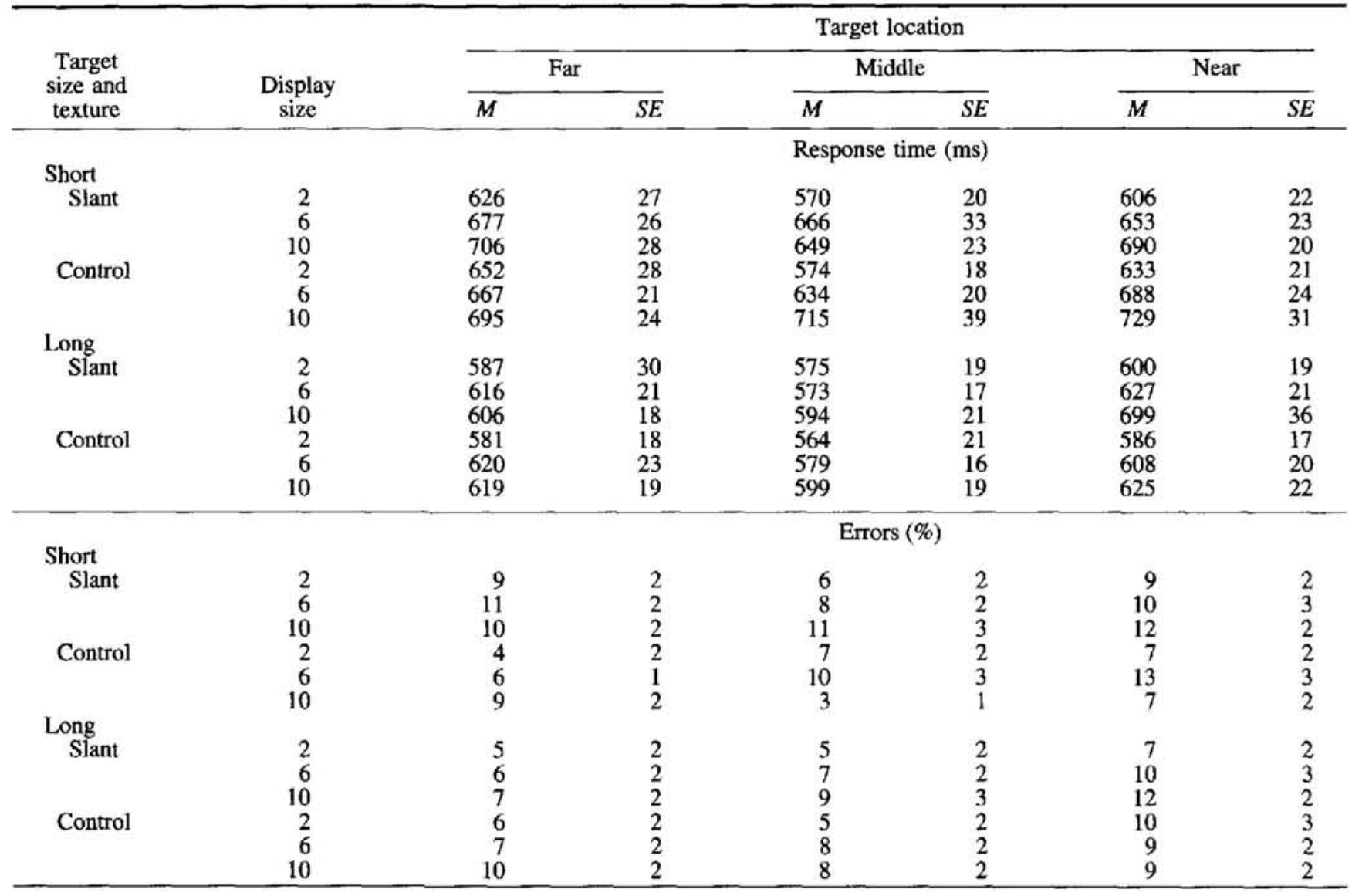

As shown in Figure 5, search for short targets in the slant condition was $21 \mathrm{~ms}$ slower, $t(58)=1.45, p<.10$, and equally accurate (mean difference $<1 \%$ error) in the far vs. near location. This difference was significant when compared with the fine versus coarse-scale textures in the con- trol condition, which yielded a $12 \mathrm{~ms}$ difference in the opposite direction, $t(58)=2.26, p<.05$. Conversely, search for long targets was $38 \mathrm{~ms}$ slower, $t(58)=2.60, p<$ .05 , and $3.8 \%$ less accurate, $t(58)=2.52, p<.05$, in the near than in the far locations. In the control conditions,

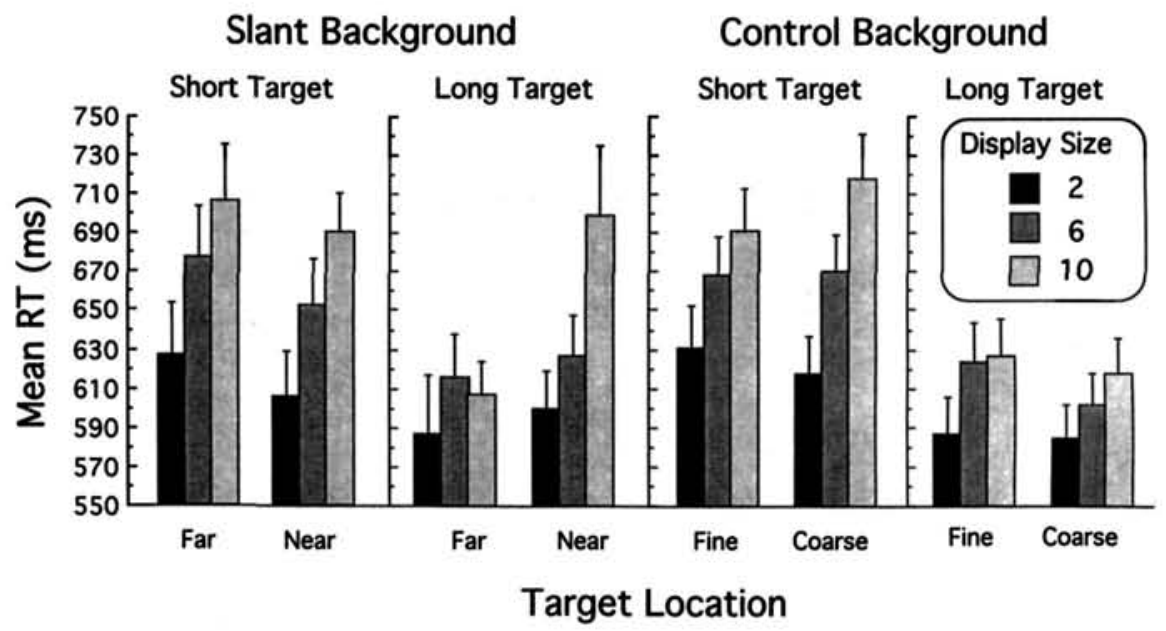

Figure 5. Mean correct response time (RT) for selected target present trials in Experiment 2. Bars in each group of three show display sizes of 2 (left bar), 6 (middle bar), and 10 (right bar). 
performance did not vary significantly for the fine versus coarse texture $(p>.05)$. These comparisons were supported in the overall ANOVA by a significant interaction of Background $\times$ Target Size $\times$ Scale-RT: $F(2,58)=3.37, p<$ .04 ; errors: $F(2,58)=1.11$.

As in the previous experiment, RT slopes were not as sensitive to the slant of the texture gradients as the mean RT measure. In the slant condition, RT slopes for the long target in the near location were significantly larger than in the far location-12.4 vs. $4.3 \mathrm{~ms}$ per item, $t(29)=2.25, p<.05$ but slopes for the short target did not vary with locationfar $=10.0$ vs. near $=10.5 \mathrm{~ms}$ per item, $t(29)<1$. In the control condition, the trend for short targets was in the opposite direction to the predicted effects of local size contrast (slopes were non-significantly larger for the coarse texture, 10.7 vs. $5.4 \mathrm{~ms}$ per item, $t[29]=1.48, p>.10$ ), whereas slopes for the long targets were similar in the fine and coarse conditions ( 4.7 vs. $4.9 \mathrm{~ms}$ per item, $t[29]<1$ ).

The size-consistency RT scores, shown in Figure 6, were significantly larger than zero for both target sizes-short: $t(89)=1.77, p<.05$; long: $t(89)=2.23, p<.05$-but did not differ significantly with target size or display size $(p>$ $.05)$. Errors showed a similar pattern, although none of the effects were significant (mean consistency score $=1.5 \%$ for short, $1.9 \%$ for long).

\section{Discussion}

These data show that there is an influence of depicted surface slant on visual search for item size even when the

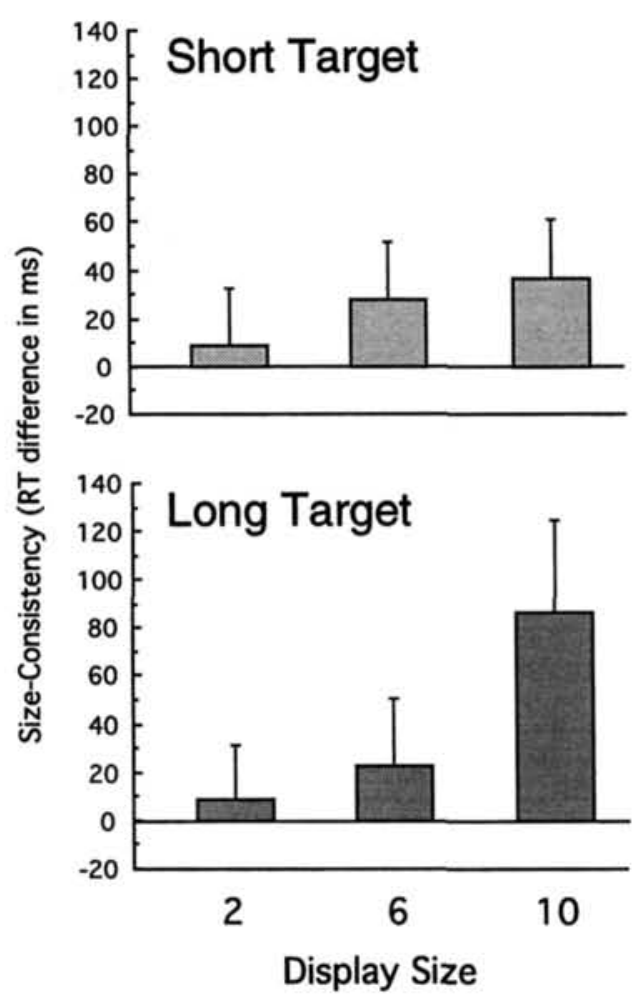

Figure 6. Size-consistency scores in Experiment 2. local contrast relations between the target and background have been controlled. It is noteworthy that the sizeconsistency scores were generally larger in Experiment 1, in which local contrast was not controlled, than in this experiment, in which it was controlled. This suggests that local contrast may play a role in these visual search experiments. The more important point, however, is that local contrast effects may serve to enhance the perception of relative object size in more naturalistic displays, in which local contrast relations and relative depth cues are correlated attributes. A second difference between experiments was that short targets showed the most consistent effects of background texture slant in Experiment 1, whereas these effects were more evident for the long targets in Experiment 2. Because other differences between short and long targets were found in Experiment 3, we will postpone discussion of these effects to the General Discussion.

\section{Experiment 3: Separate Contributions From Perspective and Compression?}

Which information in the texture gradient contributes most to the differences in visual search speed? Cutting and Millard (1984) have identified three possible sources, which they refer to as perspective (decreases in the width of textural elements along the direction of the greatest change in depicted slant) $;{ }^{4}$ compression (decreases in the height of textural elements, along the direction of the greatest change in depicted slant); and density (decreases in the distance between textural elements and increases in the number of texture elements per unit area).

Some have speculated that these dimensions play different functional roles in vision. For instance, perspective appears to be a more reliable and direct cue for surface distance, whereas compression informs more directly about local orientation changes that arise from surface curvature (Cutting \& Millard, 1984; Stevens, 1981, 1984; Witkin, 1981). Stevens (1984) even speculates that these properties may map onto separate depth and orientation representations in human vision.

How do these dimensions contribute to the subjective reports of apparent slant in texture gradients? The methods used to test this question have typically involved isolating one dimension, or pitting one against the other, and then recording participants' subjective impressions of slant (Braunstein, 1976; Braunstein \& Payne, 1969). These studies report that perspective and density have a greater influence than compression on reports of perceived slant for flat

\footnotetext{
${ }^{4}$ The texture gradients used (shown in Figure 7) were rotated $90^{\circ}$, relative to the conventional descriptions, in order to rule out influences from height in the plane. Thus, the term width is still used to refer to the size dimension that is orthogonal to the direction of slant in the image, despite the fact that it now corresponds to the vertical dimension on the page.
} 
surfaces. However, when the perception of curved surfaces has been investigated, compression has been shown to be more important (Cutting \& Millard, 1984; Todd \& Akerstrom, 1987).

In this experiment, we examined only perspective and compression, because in our displays it was not possible to isolate density (i.e., by using grid-cells as texture elements, element size and spacing were not separable). Examples of the displays are shown in Figure 7. Our primary question concerned the relative importance of these two dimensions in predicting visual search, and we examined it in three different ways. To foreshadow the results, each approach pointed to a similar answer: Relatively slower search (search for short targets among long distractors) was influenced in a synergistic way by the combination of perspective and compression, whereas more rapid search (search for long targets among short distractors) appeared to be governed by independent contributions from each dimension.

\section{Data Analyses}

A first analysis consisted of a straightforward ANOVA comparison of the size-consistency scores in the three slant conditions: combined dimensions, perspective only, and compression only.

The second analysis used Sternberg's (1969a, 1969b) additive factors (AF) method to test the models of shared versus independent information from the two dimensions (see Aks \& Enns, 1992, for a brief review of the relevant assumptions and procedures). In this test, size-consistency scores were analyzed as a function of perspective (presence, absence); compression (presence, absence); target size (short, long); item orientation (horizontal, vertical); and display size $(2,6$, and 10 items).

Finally, path analysis (PA) was used to test for dependency among perspective and compression (Blalock, 1962, 1985; Wright, 1960). This analysis was based on the pattern of simple and partial correlations among correct mean RTs from the isolated perspective (P), isolated compression (C), and combined dimension (PC) conditions.

\section{Method}

Observers, stimuli, and procedures were the same as in Experiment 1, except for the addition of displays that isolated the dimensions of perspective and compression. The six conditions compared in this experiment are shown in Figure 7: (A) combined gradient, (B) perspective gradient, (C) compression gradient, (D) uniform grid (control for the combined gradient), (E) horizontal grid (control for the perspective gradient), and (F) vertical grid (control for the compression gradient).

\section{Results}

Size-consistency scores. Target present data from the combined conditions (slant and slant control) have already been presented in Experiment 1 (see Table 1). Table 3 (perspective alone) and Table 4 (compression alone) contain
A

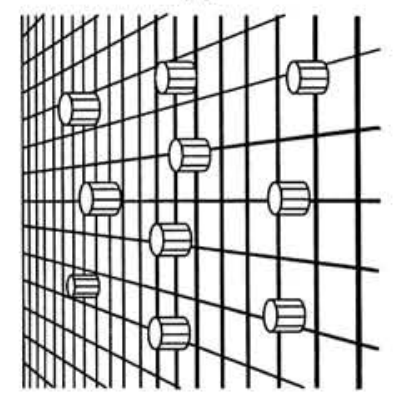

D

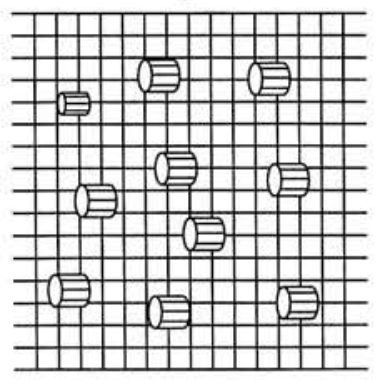

B

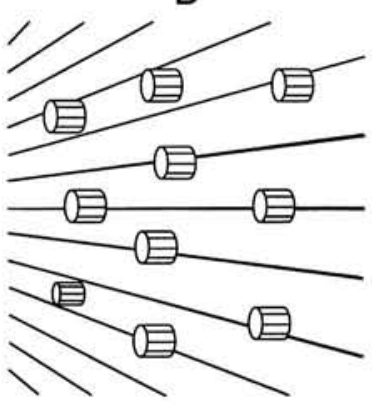

E

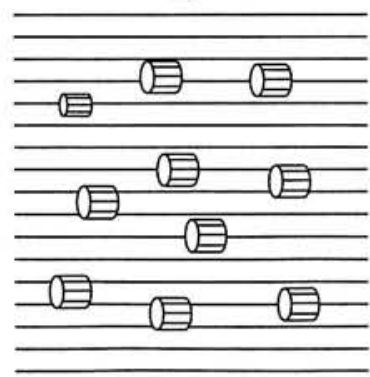

C

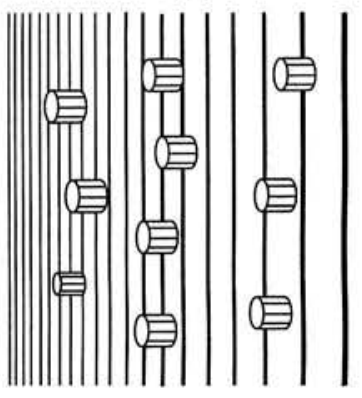

F

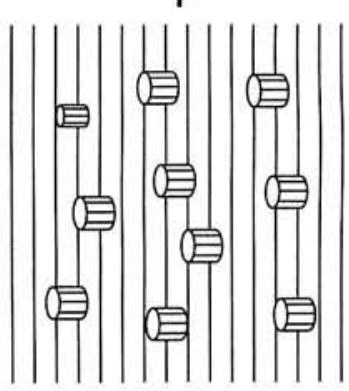

Figure 7. Examples of the 10-item target-present visual search displays in Experiment 3. (A) Combined dimensions gradient. (B) Isolated perspective gradient. (C) Isolated compression gradient. (D) Combined control gradient. (E) Perspective control gradient. (F) Compression control gradient. 
Table 3

Mean Correct Response Time and Mean Errors for the Perspective Alone Condition in Experiment 3

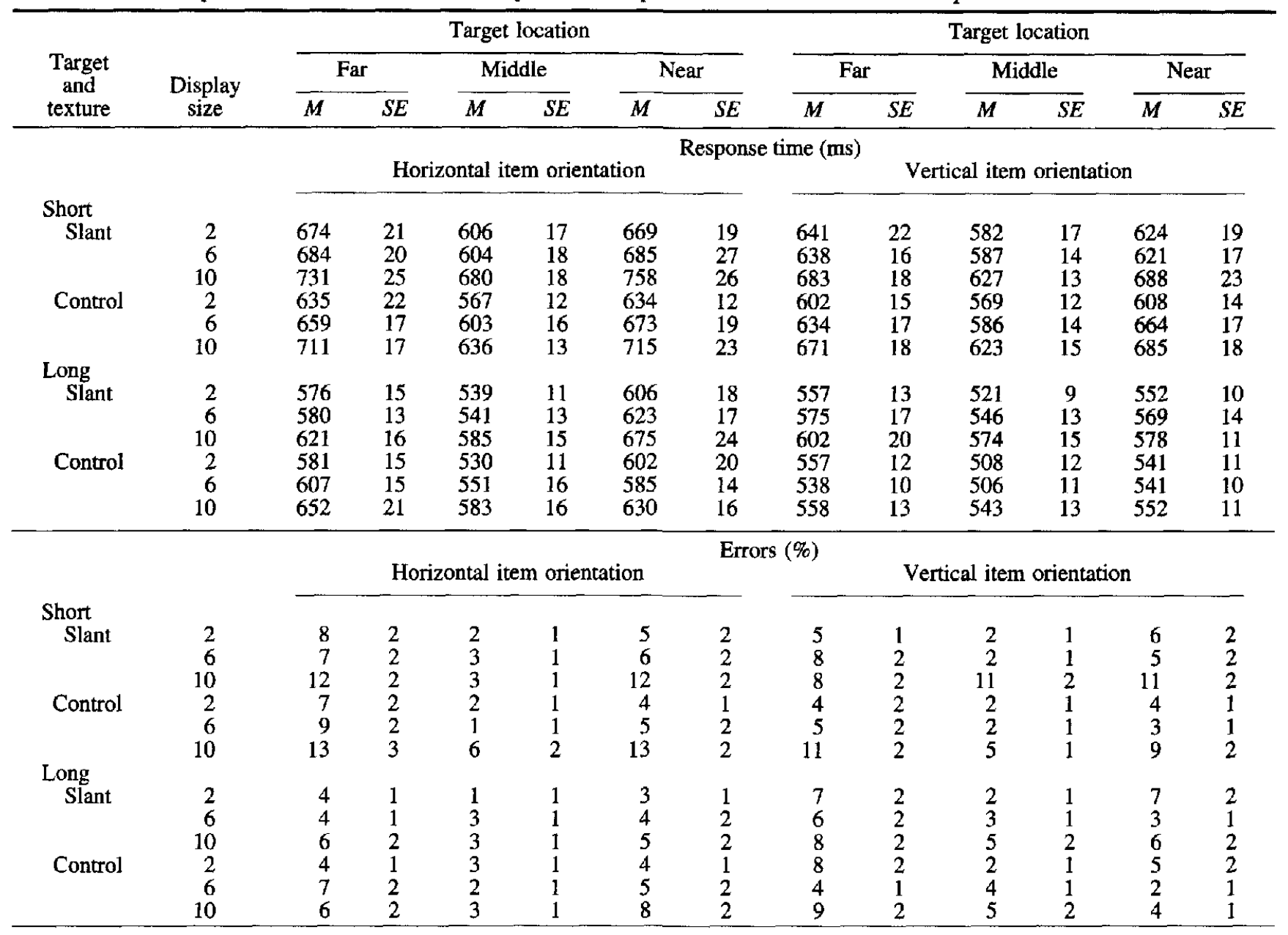

the corresponding data from the isolated texture dimensions and their control backgrounds.

Figure 8 shows the relative strength of the three texture conditions in producing a size-consistency effect. A significant main effect of texture type-RT: $F(2,76)=8.20, p<$ .001 ; errors: $F(2,76)=4.25, p<.02$ - reflected that the combined condition yielded the strongest effect $(60 \mathrm{~ms}$, $4.0 \%$ errors), whereas the perspective $(20 \mathrm{~ms},-0.40 \%$ errors) and compression conditions $(16 \mathrm{~ms}, 1.15 \%$ errors) each produced significantly smaller effects--perspective RT: $t(76)=3.32, p<.01$; perspective errors: $t(76)=$ $2.87, p<.01$; compression RT: $t(76)=3.67, p<.01$; compression errors: $t(76)=1.86, p<.07$. Short targets did not differ from long targets overall-RT: $F(1,38)=0.56$; errors: $F(1,38)=1.07$-but the Texture Type $\times$ Target Size interaction was marginal in both measures-RT: $F(2$, $76)=2.38, p<.10$; errors: $F(2,76)=2.92, p<.06-$ reflecting the larger difference between combined and isolated-dimension for short targets. As in Experiment 1 (see Table 1), there was some evidence for larger sizeconsistency effects for horizontal items, especially among the long target conditions, Target Size $\times$ Orientation interaction: $F(1,38)=3.47, p<.08$.

Additive factors. The RT means used in this analysis are shown in Figure 9. As is readily apparent, the most important finding was a significant triple interaction of Perspective $\times$ Compression $\times$ Target Size, $F(1,38)=7.33, p<$ .01. Separating this interaction by target size revealed an interactive influence of Perspective $\times$ Compression for short targets, $F(1,38)=9.61, p<.01$, and an additive one for long targets, $F(1,38)=0.37$. Both main effects were also significant-perspective: $F(1,38)=17.28, p<.001$; compression: $F(1,38)=27.38, p<.001$.

The error data supported this analysis in trend, although not always in significance. The interaction of Perspective $\times$ Compression $\times$ Target Size was significant, $F(1,38)=$ $4.70, p<.05$, as was the main effect of compression, $F(1$, $38)=6.92, p<.02$. Most important, the difference in interaction patterns between short and long targets was consistent with the RT data, thereby ruling out the possibility that these RT patterns reflected different speedaccuracy trading relations. 
Table 4

Mean Correct Response Time and Mean Errors for the Compression Alone Condition in Experiment 3

\begin{tabular}{|c|c|c|c|c|c|c|c|c|c|c|c|c|c|}
\hline \multirow{3}{*}{$\begin{array}{c}\text { Target } \\
\text { and } \\
\text { texture }\end{array}$} & \multirow{3}{*}{$\begin{array}{c}\text { Display } \\
\text { size }\end{array}$} & \multicolumn{6}{|c|}{ Target location } & \multicolumn{6}{|c|}{ Target location } \\
\hline & & \multicolumn{2}{|c|}{ Far } & \multicolumn{2}{|c|}{ Middle } & \multicolumn{2}{|c|}{ Near } & \multicolumn{2}{|c|}{ Far } & \multicolumn{2}{|c|}{ Middle } & \multicolumn{2}{|c|}{ Near } \\
\hline & & $M$ & $\overline{S E}$ & $M$ & $\overline{S E}$ & $M$ & $\overline{S E}$ & $M$ & $\overline{S E}$ & $M$ & $\overline{S E}$ & $M$ & $\overline{S E}$ \\
\hline & & \multicolumn{6}{|c|}{ Horizontal item orientation } & \multicolumn{6}{|c|}{ Vertical item orientation } \\
\hline \multicolumn{14}{|l|}{ Short } \\
\hline & 10 & 732 & 22 & 649 & 18 & 756 & 23 & 691 & 22 & 653 & 20 & 741 & 32 \\
\hline Control & 2 & 636 & 23 & 573 & 15 & 643 & 17 & 657 & 26 & 605 & 21 & 666 & 21 \\
\hline & 6 & 633 & 15 & 579 & 12 & 623 & 15 & 693 & 28 & 612 & 18 & 669 & 23 \\
\hline & 10 & 714 & 21 & 641 & 14 & 712 & 19 & 710 & 22 & 664 & 19 & 706 & 26 \\
\hline \multirow{3}{*}{$\begin{array}{l}\text { Long } \\
\text { Slant }\end{array}$} & & & & & & & & & & & & & \\
\hline & 2 & 584 & 13 & 573 & 19 & 620 & 19 & 574 & 13 & 521 & 11 & 560 & 11 \\
\hline & 6 & 622 & 25 & 553 & 12 & 635 & 27 & 563 & 11 & 530 & 12 & 562 & 14 \\
\hline \multirow{2}{*}{ Control } & & \multicolumn{12}{|c|}{ Errors (\%) } \\
\hline & & \multicolumn{6}{|c|}{ Horizontal item orientation } & \multicolumn{6}{|c|}{ Vertical item orientation } \\
\hline Short & & & & & & & & & & & & & \\
\hline Slant & 2 & 8 & 2 & 1 & 1 & 2 & 1 & 5 & 1 & 2 & 1 & 4 & 1 \\
\hline & 6 & 7 & 2 & 3 & 1 & 3 & 1 & 3 & 1 & 3 & 1 & 3 & 1 \\
\hline & 10 & 12 & 2 & 3 & 1 & 9 & 2 & 11 & 2 & 5 & 2 & 12 & 2 \\
\hline Control & 2 & 5 & 2 & 4 & 1 & 4 & 1 & 6 & $\overline{2}$ & 4 & 1 & 4 & 1 \\
\hline & 6 & 7 & 2 & 2 & 1 & 7 & 2 & 6 & 2 & 3 & 1 & 2 & 1 \\
\hline & 10 & 9 & 2 & 3 & 1 & 7 & 2 & 8 & 2 & 6 & 2 & 8 & 2 \\
\hline \multicolumn{14}{|l|}{ Long } \\
\hline Slant & 2 & 4 & 1 & 5 & 2 & 7 & 2 & 6 & 2 & 4 & 1 & 6 & 2 \\
\hline & 6 & 4 & 1 & 2 & 1 & 6 & 2 & 3 & 1 & 4 & 1 & 4 & 1 \\
\hline
\end{tabular}

Path analysis. The pattern of simple correlations for long targets indicated that perspective was the only significant predictor of combined dimension performance, $r(38)=.43, p<.01$. The nonsignificant correlation between perspective and compression, $r(38)=.22, p<.17$, indicated that the individual dimensions, if indeed both were coded, were done so in parallel. However, the absence of a significant correlation between compression and combined, $r(38)=.08$, indicated further that the temporally parallel model (independence) could be reduced to one in which perspective was the only significant predictor of performance in the combined condition, as shown in Figure 10.

The pattern of simple correlations for short targets indicated that each of the dimensions was a significant predictor of the combined condition- perspective: $r(38)=.37, p<$ .01 ; compression: $r(38)=.45, p<.01-$ as well as being correlated with one another, $r(38)=.40, p<.01$. This suggests a dependence between the two dimensions. An assessment of the partial correlations-perspective, with compression controlled: $r(38)=.22, p<.20$; compression with perspective controlled: $r(38)=.35, p<.05-$ indicated that perspective predicted the combined condition reliably only in the context of the compression variable. This pattern of correlation is thus consistent with the processing order $\mathrm{P} \rightarrow \mathrm{C} \rightarrow \mathrm{PC}$ for the short targets, as shown in Figure 10.

\section{Discussion}

The three analyses in Experiment 3 each pointed to an interesting difference between search for short and long targets. In the comparison of size-consistency effects, the combined textures had a greater influence on search for the short targets than on search for the long targets. The additive factors analysis also revealed an interdependence in the influence of the two dimensions on search for short targets, but it showed independence in the influence of these same dimensions on search for long targets. Finally, the path analysis suggested a synergistic relation between the two texture dimensions for short targets, possibly the consequence of a sequential processing of perspective followed by compression. For long targets, however, only perspective 


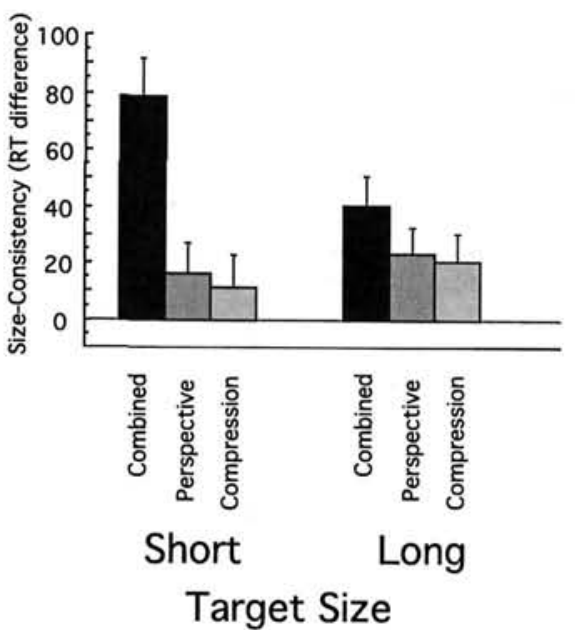

Figure 8. Size-consistency scores in Experiment 3.

contributed significantly to visual search against the combined texture.

What might account for the tendency to observe additivity (or independence) in the influence of the texture dimensions for long targets, while at the same time observing an interaction for short targets? The most obvious correlate of this difference is baseline task difficulty. Long targets were found both more rapidly ( $89 \mathrm{~ms})$ and accurately ( $2 \%$ difference in errors) than were short targets overall-RT: $F(1$, $38)=82.56, p<.001$; errors: $F(1,38)=10.63, p<$ .01 -as would be predicted from previous reports of search asymmetries for size (Treisman \& Gormican, 1988). This suggests that the interaction between texture dimensions only occurred when the search task was relatively time consuming.

This observation suggests a straightforward interpretation. Perhaps it takes some amount of time (or alternatively, attention must become spatially focused to some degree) before the information from each of the two texture dimensions can be combined. For example, at the earliest stages of vision there may be modules that analyze the information separately for the two texture dimensions. If the search task is completed before information from these modules has been integrated, then one would indeed not expect their combination to produce synergistic effects. However, if the search task is slowed for some reason (in this case because the short target is simply not as discriminable against the long distractors as is the reverse arrangement), then these modules may have sufficient opportunity to share information.

\section{General Discussion}

These visual search experiments were conducted to determine whether factors that influence the subjective perception of slant in texture gradients also influence speeded search for objects that appear to lie on such gradients. Our conclusion is that there are strong parallels between these two domains. However, there also appear to be some interesting differences in the way in which the separable dimensions of a texture gradient are processed in the earlier versus later stages of vision.

Experiments 1 and 2 showed that an important aspect of subjective texture gradient perception-size-constancy scaling of objects with perceived distance-predicted the speed of pop-out visual search for cylinders viewed against a texture gradient. Search was especially difficult when long targets appeared in near locations of the texture gradient and when short targets appeared in far locations. Control conditions (and pilot tests) showed that this effect could not be attributed to biases in the direction of scanning, nor to other monocular depth cues such as height in the plane, nor to local effects of size contrast between the scale of the search item and the scale of the background texture.

This is an important result, because it suggests that some aspects of the texture gradient were being processed involuntarily (i.e., intruding) into a stage of visual processing that is relatively rapid, spatially parallel, and automatic (Enns \& Resnick, 1991; Treisman, 1986). The slow down in search caused by the texture gradients showed further that their influence was not simply to speed up processing because a texture is somehow more "ecologically valid" than a flat background. Rather, it makes the more important point that the representations at these stages are already informed by 3-D organizational principles-access to 2-D information is

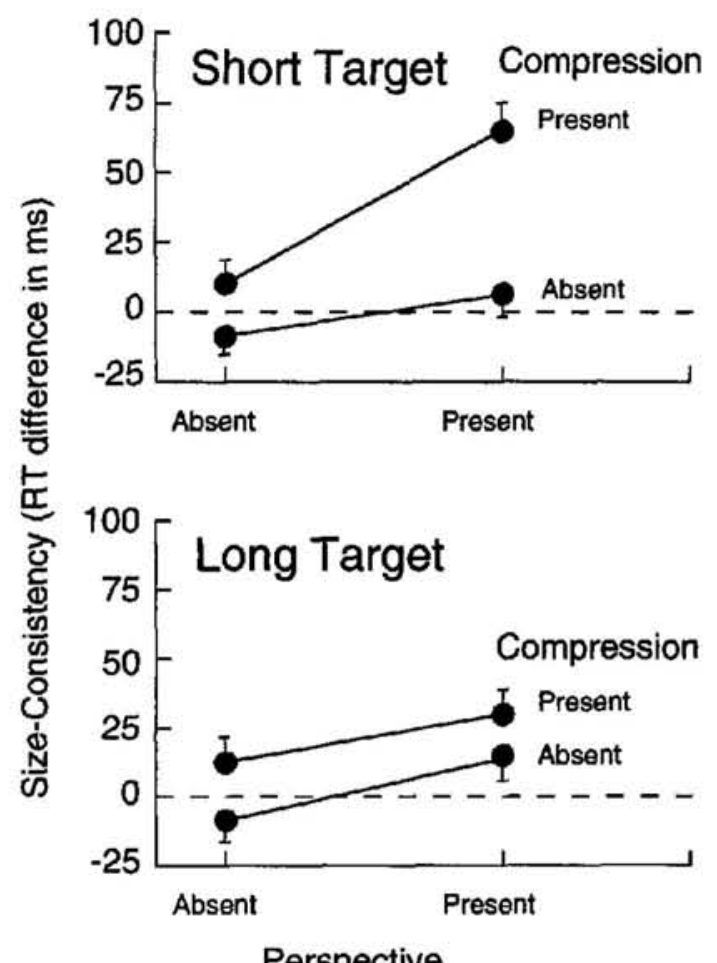

Figure 9. Additive factors method: Size-consistency scores in Experiment 3, shown separately for short and long targets, as a function of the presence versus absence of perspective and compression. 


\section{Long Targets (Rapid Search)}

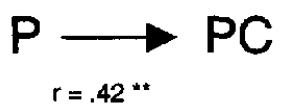

Short Targets (Slow Search)

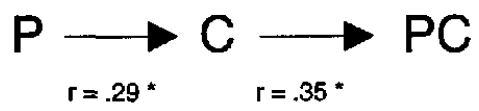

Figure 10. Path analysis: Significant partial correlations in Experiment 3, shown separately for long and short targets, with the derived paths of influence (arrows). $\mathrm{P}=$ Perspective; $\mathrm{C}=$ Compression; $\mathrm{PC}=$ Perspective and compression combined.

therefore difficult and may even be preempted (He \& Nakayama, 1992; Rensink \& Enns, 1995; Wolfe, 1994).

Experiment 3 used three different statistical techniques to assess the relative contributions of two separable dimensions of the texture gradients-perspective and compression. These tests all showed that there were separate influences of perspective and compression in the most rapid search conditions (long targets) but that their interaction increased as the search task became more difficult (short targets).

In this section we discuss the implications of these findings for theories of surface perception and for theories of rapid vision. However, we first address ourselves to two unexpected aspects of the data.

\section{Unexpected Findings}

$R T$ slope (search rate) was not reliably influenced by texture gradients. We originally chose visual search instead of a simpler task (e.g., same-different discrimination or object detection) because it appeared to promise more information. Not only would we be able to measure simple discrimination time (i.e., RT on 2-item displays), but we would be able to measure the speed with which attention could be directed to the target item (i.e., the RT slope as a function of the number of display items, or search rate). Furthermore, the very nature of the task (i.e., uncertainty about the spatial location of target and number of candidate items) ensured that observers began each trial with their attention distributed as widely as possible. Unfortunately, the slope data were too equivocal to permit a strong conclusion. There was a tendency for the size-consistency effects to diminish with increasing display size in Experiment 1, and the opposite tendency (i.e., for these effects to increase with display size) was seen in Experiment 2.

Nonetheless, we were still left with strong effects in mean RT, both when baseline measures (i.e., display size $=2$ ) or overall measures (i.e., collapsed over all display sizes) were considered. Most important, these effects of the texture gradient were observed under conditions in which observers are otherwise able to perform pop-out visual search. Future experiments will be needed to resolve the issue of whether RT slopes are also influenced under some conditions or whether the background texture gradient simply serves to influence the amount of processing "overhead" that must be completed before the search for the items is initiated.

Size-consistency effect was influenced by apparent contact between item and background. A second design de- cision we made was to disassociate the sizes of the search items from the sizes of the texture elements through the use of uniform-sized distractors. Any influence on search performance therefore had to be attributed to an involuntary processing of a task-irrelevant stimulus dimension, as is the case in the well-known Stroop effect (e.g., McLeod, 1991). That is, the effects did not depend on observers' focusing attention on the elements of the texture gradient itself (cf. Bennett \& Warren, 1993, and Smets \& Stappers, 1990).

In retrospect, it is possible that this undercut the usefulness of the search rate measure (RT slopes) for comparing conditions. As pointed out in the discussion of Experiment 1 , large numbers of same-sized distractor items (i.e., in the 6- and 10-item displays) may have produced a grouping effect that actually assisted observers in being able to ignore the texture gradient. Our subjective impressions of these displays, as well as the data, are consistent with the idea that the search items were more likely to appear suspended in a frontoparallel plane, rather than in the apparent texture plane, as the number of search items was increased. This was especially true for vertically oriented search items.

\section{Implications for Theories of Surface Perception}

This study extends J. J. Gibson's (1950a, 1950b, 1979) work on surface perception by exploring the underlying mechanisms involved in perceiving slant from texture gradients. Although it is not uncommon for theories of surface perception to propose an initial independent coding of various depth cues (e.g., Attneave, 1972; Cutting \& Millard, 1984; Marr, 1982; Stevens, 1981, 1983b), these proposals have largely been based on measures of subjective perception rather than on performance under stress of time. The present visual search data therefore provide performancebased support for these proposals. In addition, these data point to some interesting directions in which these theories could be extended.

The visual search data suggest that the perspective dimension has a more reliable influence on size discrimination than the compression dimension. This is seen most strongly in the easiest search conditions (i.e., long target); as the search task becomes more difficult (i.e., short target), the compression dimension becomes more influential. The path analysis suggests that this is because the analysis of compression is building on information already contributed by perspective.

How compatible is this story with existing models of surface perception? The most well known of these is Marr's 
(1982) three-stage model, which in the intermediate $21 / 2$-D sketch stage, includes a distinction between surface distance and surface shape. Local surface shape (orientation) is coded by the direction of a vector, whereas surface distance is indicated by the length of each vector. Thus, although computationally separable, orientation and distance are represented in an integrated fashion at the $21 / 2-\mathrm{D}$ sketch. There is nothing in the theory that predicts the primacy of one of these forms of information over the other.

Why then should perspective have primacy over compression in the most rapid search conditions? Stevens (1981, 1983b, 1984) outlined efficient ways to extract the surface properties of distance and slant from the image. In doing so, he provided strong arguments for the greater ecological validity, reliability, and computational simplicity of perspective over compression. In brief, perspective conveys information only about changes in surface distance, whereas compression contains information relevant to changes in both surface distance and surface orientation. In the present visual search task, item size was the diagnostic feature for the observer. Because surface texture always signaled a constant surface orientation (i.e., flat), only surface distance was relevant to the size-discrimination made by the observer. If the visual system indeed performs an analysis such as Stevens suggested, then the distance information contained in the isolated perspective condition and in the combined texture should be readily available and easy to use. However, in the isolated compression condition, this distance information would only be available indirectly, that is, through the more complex information signaling surface orientation (see Stevens, 1981). The present results are thus clearly consistent with this account, although they did not test it directly.

\section{Implications for Theories of Rapid Vision}

Evidence for a sensitivity to texture gradients in a pop-out search task has implications for the representations that are formed in rapid vision. One longstanding issue in this area is whether the representations accessible by psychophysical tasks correspond more closely to the retinal image or to the external objects that gave rise to the retinal projection (Palmer \& Rock, 1994). As recently as 10 to 15 years ago, most visual search theorists adhered to the former view (Beck, 1966; Julesz, 1984; Treisman \& Gelade, 1980), proposing that visual search was based on measurements of simple geometric properties (e.g., color, orientation, size, motion) in a retinotopic representation. However, with the growing number of reports that visual search is sensitive to some aspects of 3-D structure (Aks \& Enns, 1992; Enns \& Rensink, 1990a, 1990b, 1991; He \& Nakayma, 1992; Kleffner \& Ramachandran, 1992; Nakayama \& Silverman, 1986; Ramachandran, 1988), this has begun to change. For example, Treisman and Sato (1990) and Wolfe (1994) acknowledged that preattentive processes have access to representations with some 3-D information.

From this perspective, the present data are yet another example of the sensitivity of visual search mechanisms to 3-D information-size-constancy scaling based on texture gradients. However, caution should be used in interpreting this result. In itself, the demonstration of sensitivity to a texture gradient does not tell us how complete the representation actually is, nor how closely the size-constancy scaling approximates that studied under conditions of focused attention. The challenge to future models of rapid vision will be to provide biologically plausible accounts of how the beginnings of a postconstancy representation can be instantiated early in the visual stream.

\section{References}

Aks, D. J. (1993). The analysis of slant-from-texture in visual search. Unpublished doctoral dissertation, University of British Columbia, Vancouver, Canada.

Aks, D. J., \& Enns, J. T. (1992). Visual search for direction of shading is influenced by apparent depth. Perception and Psychophysics, 52, 63-74.

Ashby, F. G., \& Townsend, J. T. (1986). Varieties of perceptual independence. Psychological Review, 93, 154-179.

Attneave, F. (1972). Representations of physical space. In A. W. Melton \& E. Martin (Eds.), Coding processes in human memory (pp. 283-308). New York: Halsted Press.

Beck, J. (1966). Perceptual grouping produced by changes in orientation and shape. Science, 154, 538-540.

Beck, J. (1982). Textural segmentation. In J. Beck (Ed.,), Organization and representation in perception (pp. 285-317). Hillsdale, NJ: Erlbaum.

Bennett, D. J.,\& Warren, W. (1993). Information about environmental size affects size-scaling. Investigative Ophthalmology \& Visual Science 34, 1081.

Blalock, H. M. (1962). Four variable causal models and partial correlations. American Journal of Sociology, 68, 182-194.

Blalock, H. M. (1985). Causal models in the social sciences. New York: Aldine.

Braunstein, M. L. (1976). Depth perception through motion. New York: Academic Press.

Braunstein, M. L., \& Payne, J. W. (1969). Perspective and form ratio as determinants of relative slant judgments. Journal of Experimental Psychology, 81, 584-590.

Butler, D. L., \& Kring, A. M. (1987). Integration of features in depictions as a function of size. Perception \& Psychophysics, $41,159-164$.

Callaghan, T. C. (1989). Interference and dominance in texture segregation: Hue, geometric form, and line orientation. Perception \& Psychophysics, 46, 299-311.

Callaghan, T. C., Lasaga, M. I., \& Gamer, W. R. (1986). Visual texture segregation based on orientation and hue. Perception \& Psychophysics, 39, 32-38.

Carrasco, M., Evert, D. L., Chang, I., \& Katz, S. M. (1995). The eccentricity effect: Target eccentricity affects performance on conjunction searches. Perception and Psychophysics, 57, (8), 1241-1261.

Cornsweet, T. N. (1962). The staircase-method in psychophysics. American Journal of Psychology, 75, 485-491.

Cutting, J. E., \& Millard, R. T. (1984). Three gradients and the perception of flat and curved surfaces. Journal of Experimental Psychology: General, 113, 198-216.

Duncan, J., \& Humphreys, G. W. (1989). Visual search and stimulus similarity. Psychological Review, 96, 433-458.

Enns, J. T., \& Rensink, R. A. (1990a). Scene-based properties influence visual search. Science, 247, 721-723.

Enns, J. T., \& Rensink, R. A. (1990b). Sensitivity to three- 
dimensional orientation in visual search. Psychological Science, 1, 323-326.

Enns, J. T., \& Rensink, R. A. (1991). Preattentive recovery of three-dimensional orientation from line drawings. Psychological Review, 98, 335-351.

Enns, J. T., \& Rensink, R. A. (1992). VScope: General purpose tachistoscope for the Macintosh. Vancouver: Micropsych.

Flock, H. R. (1965). Optical texture and linear perspective as stimuli for slant perception. Psychological Review, 72, 505-514.

Gibson, J. J. (1950a). The perception of the visual world. Boston: Houghton Mifflin.

Gibson, J. J. (1950b). The perception of visual surfaces. American Journal of Psychology, 63, 367-384.

Gibson, J. J. (1979). The ecological approach to visual perception. Boston: Houghton Mifflin.

Green, M. (1992). Visual search, visual streams, and visual architectures. Perception \& Psychophysics, 50, 388-403.

He, Z. J., \& Nakayama, K. (1992). Surfaces versus features in visual search. Nature, 359, 231-233.

Humphreys, G. W., Quinlan, P. T., \& Riddoch, M. J. (1989). Grouping processes in visual search: Effects with single- and combined-feature targets. Joumal of Experimental Psychology: General, 118, 258-279.

Julesz, B. (1984). A brief outline of the text on theory of human vision. Trends in Neuroscience, 7, 41-45.

Kleffner, D., \& Ramachandran, V. S. (1992). On the perception of shape from shading. Perception \& Psychophysics, 52, 18-36.

Leibowitz, H., \& Bourne, L. (1956). Time and intensity as determiners of perceived shape. Journal of Experimental Psychology, $51,277-281$

Marr, D. (1982). Vision. San Francisco: Freeman.

McLeod, C. M. (1991). Half a century of research on the Stroop effect: An integrated review. Psychological Bulletin, 109, 163203.

Nakayama, K., \& Silverman, G. H. (1986). Serial and parallel processing of visual feature conjunctions. Nature, 320, 264265.

Nothdurft, C. (1992). Feature analysis and the role of similarity in preattentive vision. Perception and Psychophysics, 52, 355-375.

Palmer, S., \& Rock, I. (1994). Rethinking perceptual organization: The role of uniform connectedness. Psychonomic Bulletin and Review, 1, 29-55.

Pizlo, Z., \& Rosenfeld, A. (1992). Recognition of planar shapes from perspective images using contour-based invariants. $\mathrm{CV}$ GIP: Image Understanding, 56, 330-350.

Poisson, M. E., \& Wilkinson, F. (1992). Distractor ratio and grouping processes in visual conjunction search. Perception, 21, 21-38.

Pringle, R., \& Uhlarik, J. (1982). Comparative judgments of distal size: A chronometric analysis. Perception and Psychophysics, $32,178-186$.

Ramachandran, V.S., (1988). Perceiving shape from shading. Scientific American, 259, 76-83.

Rensink, R. A., \& Enns, J. T. (1995). Preemption effect in visual search: Evidence for low-level grouping. Psychological Review, $102,101-130$.

Sagi, D. (1990). Detection of an orientation singularity in Gabor textures: Effects of signal density and spatial frequency. Vision Research, 30, 1377-1388.

Sagi, D., \& Julesz, J. (1987). Short-range limitations on detection of feature differences. Spatial Vision, 2, 39-49.

Smets, G. J. F., \& Stappers, P. J. (1990). Do invariants or features determine the conspicuity of forms? In D. Brogan (Ed.), Visual search (pp. 29-35). London: Taylor \& Francis.

Sternberg, S. (1969a). The discovery of processing stages: Extensions of Donders' method. In W. G. Koster (Ed.), Attention and performance (Vol. 2, pp. 276-315). Amsterdam: NorthHolland.

Sternberg, S. (1969b). Memory-scanning: Mental processes revealed by reaction-time experiments. American Scientist, 57, 421-457.

Stevens, K. A. (1981). The information content of texture gradients. Biological Cybernetics, 42, 95-105.

Stevens, K. A. (1983a). Surface tilt (the direction of slant): A neglected psychophysical variable. Perception \& Psychophysics, 33, 241-250.

Stevens, K. A. (1983b). Slant-tilt: The visual encoding of surface orientation. Biological Cybernetics, 46, 183-195.

Stevens, K. A. (1984). On gradients and texture "gradients." Journal of Experimental Psychology: Human Perception and Performance, 10, 217-220.

Tatsumi, K., \& Okamura, N. (1988). Dynaperspective: $3 D$ modeling, design and presentation. Foster City, CA: Dynaware.

Todd, J. T., \& Akerstrom, R. A. (1987). Perception of threedimensional form from patterns of optical texture. Journal of Experimental Psychology: Human Perception and Performance, $13,242-255$.

Treisman, A. (1982). Perceptual grouping and attention in visual search for features and objects. Journal of Experimental Psychology: Human Perception and Performance, 8, 194-214.

Treisman, A. (1986). Preattentive processing in vision. In A. Rosenfeld (Ed.), Human and machine vision II (pp. 313-334). Boston: Academic Press.

Treisman, A., Cavanagh, P., Fischer, B., Ramachandran, V. S., \& von der Heydt, R. (1990). Form perception and attention: Striate cortex and beyond. In L. Spillman \& J. S. Wemer (Eds.), Visual perception: The neurophysiological foundations (pp. 273-316). New York: Academic Press.

Treisman, A., \& Gelade, G. (1980). A feature integration theory of attention. Cognitive Psychology, 12, 97-136.

Treisman, A., \& Gormican, S. (1988). Feature analysis in early vision: Evidence from search asymmetries. Psychological Review, 95, 15-48.

Treisman, A., \& Sato, S. (1990). Conjunction search revisited. Journal of Experimental Psychology: Human Perception and Performance, 16, 459-478.

Uhlarik, J., Pringle, R., Jordan, K., \& Misceo, G. (1980). Sizescaling in two-dimensional pictorial arrays. Perception and Psychophysics, 27, 60-70.

Witkin, A.P. (1981). Recovering surface shape and orientation from texture. Artificial Intelligence, 17, 17-45.

Wolfe, J. M. (1994). Guided search 2.0: A revised model of visual search. Psychonomic Bulletin \& Review, 1, 202-238.

Wolfe, J. M., Cave, K. R., \& Franzel, S. L. (1989). Guided search: An alternative to the feature integration model for visual search. Journal of Experimental Psychology: Human Perception and Performance, 15, 419-433.

Wright, S. (1960). Path coefficients and path regressions: Alternate or complementary concepts? Biometrics, 189-202.

Received June 28, 1994

Revision received April 10, 1995 Accepted September 12, 1995 